\title{
一种适合野外使用的被子植物分子标本干燥方式
}

\author{
沈风娇 任倩倩 董 琦 朱 丽 张建芳 杨 婧 张 再 梁红柱 赵建成 \\ 石 硕*
}

河北师范大学生命科学学院, 石家庄 050024

摘 要 该研究通过比较不同干燥方式对被子植物分子标本的影响, 试图得到一种野外采集过程中可以替代硅胶干燥法的 更为便捷的植物分子标本的干燥方法。选取 $40 、 80$ 和 $150{ }^{\circ} \mathrm{C}$ 烘干和吸水纸压制干燥、硅胶干燥法对日本晚樱(Prunus serrulata var. lannesiana)和山麦冬(Liriope spicata)两种植物的新鲜叶片进行干燥处理, 提取各种处理样品的DNA, 并将DNA进行电泳 检测、分光光度计检测及PCR扩增, 以此评价不同的干燥方式对植物基因组DNA的影响。分光光度计检测及总DNA电泳结果 显示, 经40 ${ }^{\circ} \mathrm{C}$ 烘干或硅胶干燥处理的样品总DNA浓度及长片段DNA浓度较其他干燥方式高; PCR产物浓度统计学分析显示, $40{ }^{\circ} \mathrm{C}$ 烘干处理的样品PCR产物浓度高于其他干燥方式。基于以上结果, 建议在野外采集被子植物分子标本时, 使用 $40{ }^{\circ} \mathrm{C}$ 烘 干干燥法对分子标本进行干燥处理, 避免分子标本快速降解以及硅胶干燥法的污染问题，同时可节省携带、更换大量硅胶材 料所耗费的人力。

关键词 被子植物; 野外; 分子标本; DNA; 烘干; 硅胶

引用格式: 沈风娇, 任倩倩, 董琦, 朱丽, 张建芳, 杨婧, 张再, 梁红柱, 赵建成, 石硕 (2017). 一种适合野外使用的被子植物分子标本干燥方式. 植物 生态学报, 41, 787-794. doi: 10.17521/cjpe.2016.0322

\section{A new angiosperms molecular specimen treatment method for field use}

SHEN Feng-Jiao, REN Qian-Qian, DONG Qi, ZHU Li, ZHANG Jian-Fang, YANG Jing, ZHANG Ran, LIANG Hong-Zhu, ZHAO Jian-Cheng, and SHI Shuo*

College of Life Science, Hebei Normal University, Shijiazhuang 050024, China

\begin{abstract}
Aims This study aims to identify a more convenient drying method for obtaining molecular specimen of angiosperms in the field than the conventional silica gel drying method.

Methods The leaves of Prunus serrulata var. lannesiana and Liriope spicata were dried under temperatures of $150{ }^{\circ} \mathrm{C}, 80^{\circ} \mathrm{C}, 40^{\circ} \mathrm{C}$ as well as under natural conditions, and by the silica gel drying method, respectively. The DNA extracts of various specimens were then analyzed using techniques of spectrophotometer detection, electrophoresis and PCR to evaluate the impacts of different drying treatments to the genomic DNA of testing plants.

Important findings The concentrations of total DNA were higher for the specimens dried at $40{ }^{\circ} \mathrm{C}$ treatment and by the silica gel drying method than other treatments when assessed by the techniques of spectrophotometer detection and electrophoresis. The concentration of PCR products was highest in the specimens dried at $40{ }^{\circ} \mathrm{C}$. Based on the results, the $40{ }^{\circ} \mathrm{C}$ drying can be recommended for obtaining molecular specimens of angiosperms because of its minimum degree of degradation, for convenience of operation and avoiding carrying large amounts of silica gel in field investigations.
\end{abstract}

Key words angiosperms; field; molecular specimen; DNA; drying; silica gel

Citation: Shen FJ, Ren QQ, Dong Q, Zhu L, Zhang JF, Yang J, Zhang R, Liang HZ, Zhao JC, Shi S (2017). A new angiosperms molecular specimen treatment method for field use. Chinese Journal of Plant Ecology, 41, 787-794. doi: 10.17521/cjpe.2016.0322

提取高品质的DNA是植物材料用于分子生物 学研究的先决条件, 对用于DNA提取的植物材料进 行处理的理想方式是使用低温或液氮速冻处理, 但
这一方法在野外不方便实施(Liston et al., 1990; 何 天明等, 2004)。前人对野外如何处理分子标本(专门 用于提取DNA的植物组织标本)这一问题进行了探

收稿日期Received: 2016-10-17 接受日期Accepted: 2017-06-01

* 通信作者Author for correspondence (E-mail: shishuo@hebtu.edu.cn) 
索, 发现干燥处理后的分子标本可用于DNA提取 (Doyle \& Dickson, 1987), 而且分子标本经干燥处理 后便于储存和携带, 此类处理方式特别适合野外 使用。

学者们提出了不同干燥分子标本的处理方法, 如酒精法(Taggart et al., 1991)、硅胶干燥法(Chase \& Hills, 1991)、硅藻土法、沙埋法(Cliquet \& Jackson, 1997)等。研究发现, 分子标本干燥过程中DNA会发 生不同程度的降解(Staats et al., 2011), 特别是标本 的干燥方式严重影响分子标本中DNA的品质与总 量(Särkinen et al., 2012), 而硅胶干燥法的效果较好, 优于上述其他分子标本干燥方法(Cliquet \& Jackson, 1997; 蔡秀珍等, 2008)。野外采集标本时, 使用变色 硅胶可将新鲜叶片较快干燥, 减少DNA降解, 使用 也较为方便, 于是硅胶干燥法在处理分子标本时被 广泛使用(Wang et al., 1996; Xie et al., 1998; Alexander et al., 2007; Xu et al., 2015)。虽然使用硅胶干 燥法处理后的标本可以得到较高品质的DNA, 但是 使用硅胶干燥法也存在许多不便: 1)硅胶密度较大, 野外远距离采样时不便随身大量携带; 2)硅胶吸水 后更换不及时会导致标本干燥不彻底, 影响分子标 本品质, 而及时更换硅胶会大大增加工作量; 3)使 用后的硅胶再次使用前, 需对其进行干燥处理, 回 收利用的硅胶容易使样品之间相互污染。因此, 在 野外标本采集时使用硅胶干燥法处理分子标本具有 较大的局限性。那么是否有更适于野外使用的分子 标本干燥方式呢?

我们在长期的野外采集实践中, 发现烘干法是 一个可用的选择。前人做过尝试性的研究, 发现烘 干处理后的标本也可提取到较高品质的DNA (靖相 密等, 2008)。在本研究中, 我们对包括硅胶干燥法 在内的几种干燥方式进行研究, 比较不同干燥方式 对分子标本的影响; 并结合在野外可供使用的设备 设置实验的具体方案, 试图得到一种在野外采集过 程中可以替代硅胶干燥法的更为便捷的被子植物分 子标本干燥方法, 供相关人员在野外标本采集过程 中参考使用。

\section{1 材料和方法}

\section{1 材料}

选取日本晚紧(Prunus serrulata var. lannesiana) 及山麦冬(Liriope spicata)两种植物。日本晚紧为真
双子叶类的木本植物, 叶纸质; 山麦冬为单子叶类 的草本植物, 叶肉质。本实验选取了生活型、系统 发育位置和叶片质地相对具代表性的这两种植物进 行研究。山麦冬剪取叶片中部以上的部位, 日本晚 樱选取同一植株上的叶片并去除主脉。日本晚樱、 山麦冬凭证标本分别为: 任倩倩, 20151107001; 任 倩倩, 20151107002。凭证标本存放于河北师范大学 植物标本馆(HBNU)。

\section{2 方法}

\subsection{1 材料处理}

(1)将日本晚樱与山麦冬叶片上的尘土擦拭干 净, 以免影响其质量。

(2)叶片擦干后分为 5 份, 分别用 $150{ }^{\circ} \mathrm{C}$ 烘干(模 拟极端温度), $80{ }^{\circ} \mathrm{C}$ 烘干(模拟烘干机近通风口温度), $40{ }^{\circ} \mathrm{C}$ 烘干(模拟电热毯温度, 吹风机及小型便携烘 干机远通风口温度), 吸水纸压制干燥和硅胶干燥5 种干燥方法处理。同种植物样品经不同方式干燥处 理所需时间可能不同, 但在处理后应保证其失水率 一致(干燥处理完成时样品质量不再变化: 根据前 期实验的结果, 日本晚樱失水率约为 $62 \%$, 山麦冬 失水率约为 $67 \%$ )。干燥后的实验材料在密封袋中用 硅胶密封保存于 $4{ }^{\circ} \mathrm{C}$ 冰箱备用。

(3) 用分析天平分别称取 5 种不同干燥处理的实 验材料, 每种处理 16 个重复, 共 80 个样品, 每个样 品各取 $10 \mathrm{mg}$ 。将样品置于 $2.0 \mathrm{~mL}$ EP管中, 使用高 通量组织研磨仪(SCIENTZ-48)将样品快速研磨成 粉末状后立即进行DNA提取。

\subsubsection{DNA的提取}

实验使用 $\mathrm{mCTAB}$ 法(李金璐等, 2013)提取叶片 的DNA, 此法有产率高、品质较好、PCR扩增成功 率高、成本低、通用性好等优点, 且实验者具有较 成熟的操作经验, 可保证操作的稳定性, 使研究结 果更具实践指导意义。

\subsubsection{DNA的产率和品质检测}

1.2.3.1 DNA 检测使用琼脂糖凝胶电泳检测 DNA的片段大小、降解情况及浓度, 使用微量分光 光度计(NanoDrop 2000c, Thermo, Madison, USA)对 样品进行检测, 记录OD260/280值与DNA的浓度值 用以评估DNA的纯度与浓度。

1.2.3.2 PCR体外扩增 本实验采用引物 $r b c \mathrm{~L}-\mathrm{af}$ 和 $r b c \mathrm{~L}-1351 \mathrm{R}$ 对 DNA进行 PCR, 引物序列及 PCR扩增 程序参考Heenan等(2012)研究。

www.plant-ecology.com 
1.2.3.3 统计学分析 本实验使用 Image $\mathrm{J}$ 软件将 PCR 扩增结果定量分析, 使用STATISTICA统计学 软件将分光光度计检测及PCR 扩增所得到的数据 (OD260/280、DNA浓度及PCR产物浓度)进行统计学 分析, 并通过多重比较字母标记法(邱念伟等, 2015) 将所得结果进行分析。

\section{2 结果}

\subsection{5 种不同干燥处理的DNA品质统计及分析}

\subsection{1 分光光度计检测总DNA}

用分光光度计检测总DNA品质，如表1所示： 日本晚樱OD260/280值均在 1.70 左右, DNA浓度在 200-500 $\mathrm{ng} \cdot \mu \mathrm{L}^{-1}$ 之间; 山麦冬的 OD260/280值在 1.90 左右, DNA浓度在 $40-250 \mathrm{ng} \cdot \mu \mathrm{L}^{-1}$ 之间。

将 5 种不同干燥方式处理后所得到的数据进行 统计学分析(表1), 比较日本晚樱及山麦冬的DNA 浓度, 结果显示日本晚榄经吸水纸压制干燥后DNA 浓度显著低于其余4种干燥方式 $(p<0.05)$; 说明日 本晚樱经吸水纸压制干燥后提取的DNA浓度较低, 经其他4种干燥方式处理后提取的DNA浓度较高。

山麦冬经吸水纸压制干燥后DNA浓度显著低于硅 胶干燥, 40 和 $150{ }^{\circ} \mathrm{C}$ 烘干干燥, 差异显著 $(p<0.05)$; $80{ }^{\circ} \mathrm{C}$ 烘干的DNA浓度显著低于吸水纸压制干燥, 说明山麦冬经硅胶干燥, 40 和 $150{ }^{\circ} \mathrm{C}$ 烘干提取的 DNA浓度较高, 吸水纸压制法提取的DNA浓度稍 低, $80{ }^{\circ} \mathrm{C}$ 烘干提取的DNA浓度最低。

\subsection{2 基因组DNA的电泳检测}

从琼脂糖凝胶电泳检测结果(图1, 图2)可以看 出, 经 150 和 $80{ }^{\circ} \mathrm{C}$ 烘干处理的样品DNA在胶孔内残 留少, 说明这两种干燥方式提取的DNA较纯。

5 种不同干燥方式处理后DNA电泳检测均可检
测到DNA的存在(图1、图2), 日本晚樱和山麦冬经 $40{ }^{\circ} \mathrm{C}$ 烘干、硅胶干燥后所得长片段条带(接近胶孔 位置的条带, 胶孔在胶图上部)最亮; 吸水纸压制 干燥法处理所得的长片段条带稍暗; $150{ }^{\circ} \mathrm{C}$ 烘干 处理所得的长片段条带最暗。日本晚樱经 $80{ }^{\circ} \mathrm{C}$ 烘 干后提取的长片段DNA条带较亮，而山麦冬提取 的长片段DNA较暗。这说明日本晚樱与山麦冬经 $40{ }^{\circ} \mathrm{C}$ 烘干与硅胶干燥处理所得的长片段DNA浓 度最大, 吸水纸压制干燥法处理所得的长片段 DNA浓度稍低, 经 $150{ }^{\circ} \mathrm{C}$ 烘干所得的长片段DNA 浓度最低, 降解严重。日本晚樱经 $80{ }^{\circ} \mathrm{C}$ 烘干所得 的长片段DNA浓度较大，而山麦冬经 $80{ }^{\circ} \mathrm{C}$ 烘干 所得的长片段DNA浓度较低。

\subsection{PCR体外扩增电泳检测}

使用 Image J软件将PCR扩增结果定量分析，再 将PCR产物浓度进行统计分析(表1), 可以看出, 日 本晚樱 $40{ }^{\circ} \mathrm{C}$ 烘干处理后PCR产物的浓度显著高于 硅胶干燥、吸水纸压制干燥、 $80{ }^{\circ} \mathrm{C}$ 烘干 $(p<0.05)$; 硅胶干燥、吸水纸压制干燥、 $80{ }^{\circ} \mathrm{C}$ 烘干 3 种干燥方 式处理后体外扩增的浓度无显著性差异 $(p>0.05)$; $150{ }^{\circ} \mathrm{C}$ 烘干处理后PCR产物浓度显著低于硅胶干 燥、吸水纸压制干燥、 $80{ }^{\circ} \mathrm{C}$ 烘干 $(p<0.05)$ 。山麦冬 $40{ }^{\circ} \mathrm{C}$ 烘干处理后 PCR 产物浓度显著高于吸水纸压 制干燥、硅胶干燥 $(p<0.05)$; 吸水纸压制干燥、硅 胶干燥两种干燥方式处理后PCR产物浓度无显著性 差异 $(p>0.05) ; 80{ }^{\circ} \mathrm{C}$ 烘干处理后PCR产物浓度显著 低于吸水纸压制干燥、硅胶干燥两种干燥方式; 150 ${ }^{\circ} \mathrm{C}$ 烘干处理后PCR产物浓度显著低于 $80{ }^{\circ} \mathrm{C}$ 烘干 $(p$ $<0.05)$ 。这说明日本晚樱和山麦冬经 $40{ }^{\circ} \mathrm{C}$ 烘干处理 后PCR产物浓度最高, 硅胶干燥和吸水纸压制干燥 法处理后PCR产物浓度稍低, $150{ }^{\circ} \mathrm{C}$ 烘干处理PCR

表1 日本晚樱和山麦冬分子标本经不同干燥处理后DNA纯度、浓度及PCR产物浓度的比较(平均值土标准偏差)

Table 1 Comparisons of DNA purity, concentration and the concentration of PCR products in the specimens of Prunus serrulata var. lannesiana and Liriope spicata obtained with different drying methods (mean $\pm S D)$

\begin{tabular}{|c|c|c|c|c|c|c|}
\hline \multirow{2}{*}{$\begin{array}{l}\text { 干燥方式 } \\
\text { Drying method }\end{array}$} & \multicolumn{3}{|c|}{ 日本晚樱 Prunus serrulata var. lannesiana } & \multicolumn{3}{|c|}{ 山麦冬 Liriope spicata } \\
\hline & OD260/280 & $\operatorname{DNA}\left(\mathrm{ng} \cdot \mu \mathrm{L}^{-1}\right)$ & $\operatorname{PCR}\left(\mathrm{ng} \cdot \mu \mathrm{L}^{-1}\right)$ & OD260/280 & $\operatorname{DNA}\left(\mathrm{ng} \cdot \mu \mathrm{L}^{-1}\right)$ & $\operatorname{PCR}\left(\mathrm{ng} \cdot \mu \mathrm{L}^{-1}\right)$ \\
\hline 150 & $1.83 \pm 0.17^{\mathrm{a}}$ & $451.24 \pm 150.91^{\mathrm{a}}$ & $13.94 \pm 3.97^{\mathrm{c}}$ & $2.03 \pm 0.04^{\mathrm{a}}$ & $211.43 \pm 64.31^{\mathrm{a}}$ & $0.74 \pm 2.30^{\mathrm{d}}$ \\
\hline 80 & $1.80 \pm 0.13^{\mathrm{a}}$ & $376.13 \pm 121.04^{\mathrm{a}}$ & $34.48 \pm 9.42^{b}$ & $1.83 \pm 0.16^{\mathrm{b}}$ & $80.64 \pm 48.16^{\mathrm{c}}$ & $16.51 \pm 17.49^{\circ}$ \\
\hline 40 & $1.74 \pm 0.16^{\mathrm{ab}}$ & $470.44 \pm 228.50^{\mathrm{a}}$ & $49.07 \pm 4.83^{\mathrm{a}}$ & $1.90 \pm 0.08^{\mathrm{ab}}$ & $241.41 \pm 88.07^{\mathrm{a}}$ & $57.64 \pm 6.51^{\mathrm{a}}$ \\
\hline Y & $1.73 \pm 0.09^{\mathrm{ab}}$ & $291.64 \pm 90.77^{b}$ & $38.38 \pm 4.75^{\mathrm{b}}$ & $1.93 \pm 0.14^{\mathrm{ab}}$ & $160.01 \pm 22.95^{\mathrm{b}}$ & $46.98 \pm 8.22^{\mathrm{b}}$ \\
\hline $\mathrm{S}$ & $1.64 \pm 0.10^{\mathrm{b}}$ & $432.59 \pm 167.67^{\mathrm{a}}$ & $39.95 \pm 5.82^{\mathrm{b}}$ & $1.90 \pm 0.24^{\mathrm{ab}}$ & $252.33 \pm 61.74^{\mathrm{a}}$ & $43.19 \pm 8.72^{b}$ \\
\hline
\end{tabular}

$150,150{ }^{\circ} \mathrm{C}$ 烘干处理; $80,80{ }^{\circ} \mathrm{C}$ 烘干处理; $40,40{ }^{\circ} \mathrm{C}$ 烘干处理; $\mathrm{Y}$, 吸水纸压制干燥; $\mathrm{S}$, 硅胶干燥。 DNA, DNA浓度; PCR, PCR产物浓度。同列不同小写 字母表示差异显著 $(p<0.05)$ 。

150 , drying at $150{ }^{\circ} \mathrm{C} ; 80$, drying at $80{ }^{\circ} \mathrm{C} ; 40$, drying at $40{ }^{\circ} \mathrm{C}$; Y, natural drying; S, silica gel drying. DNA, DNA concentration; PCR, concentration of PCR products. Values designated by different lowercase letters are significant different within the same columns $(p<0.05)$. 

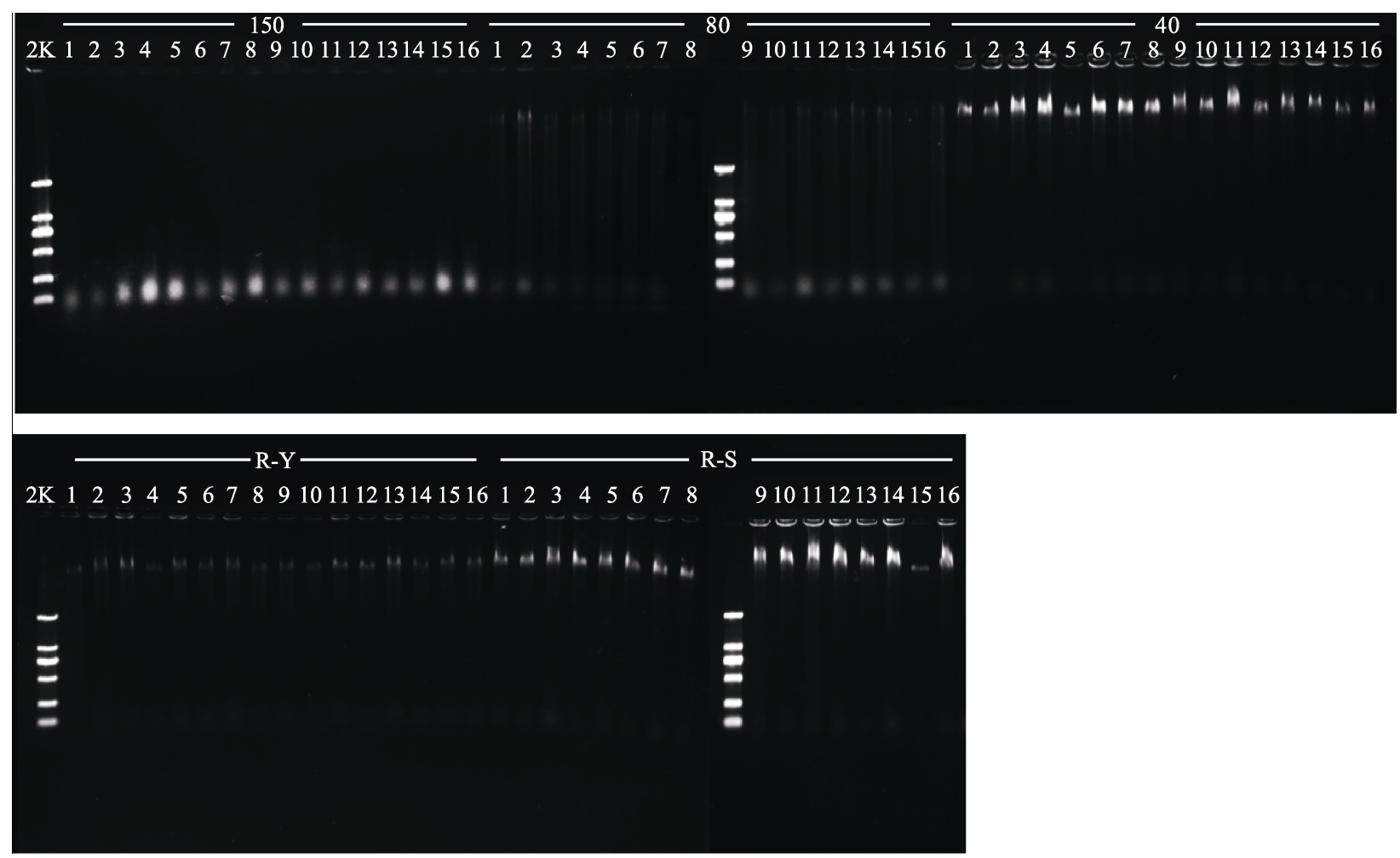

图15种不同干燥方式处理的日本晚樱(R)总DNA电泳图。150,150 ${ }^{\circ} \mathrm{C}$ 烘干处理; $80,80{ }^{\circ} \mathrm{C}$ 烘干处理; $40,40{ }^{\circ} \mathrm{C}$ 烘干处理; Y, 吸水纸压制干燥; S, 硅胶干燥; 2K, DNA ladder中最长的DNA片段为2 $000 \mathrm{bp}$ 。

Fig. 1 Genomic DNA in specimens of Prunus serrulata var. lannesiana (R) obtained with five different drying methods. 150, drying at $150{ }^{\circ} \mathrm{C} ; 80$, drying at $80^{\circ} \mathrm{C} ; 40$, drying at $40{ }^{\circ} \mathrm{C}$; Y, natural drying; $\mathrm{S}$, silica gel drying; $2 \mathrm{~K}, 2 \mathrm{~kb}$ plus DNA ladder.
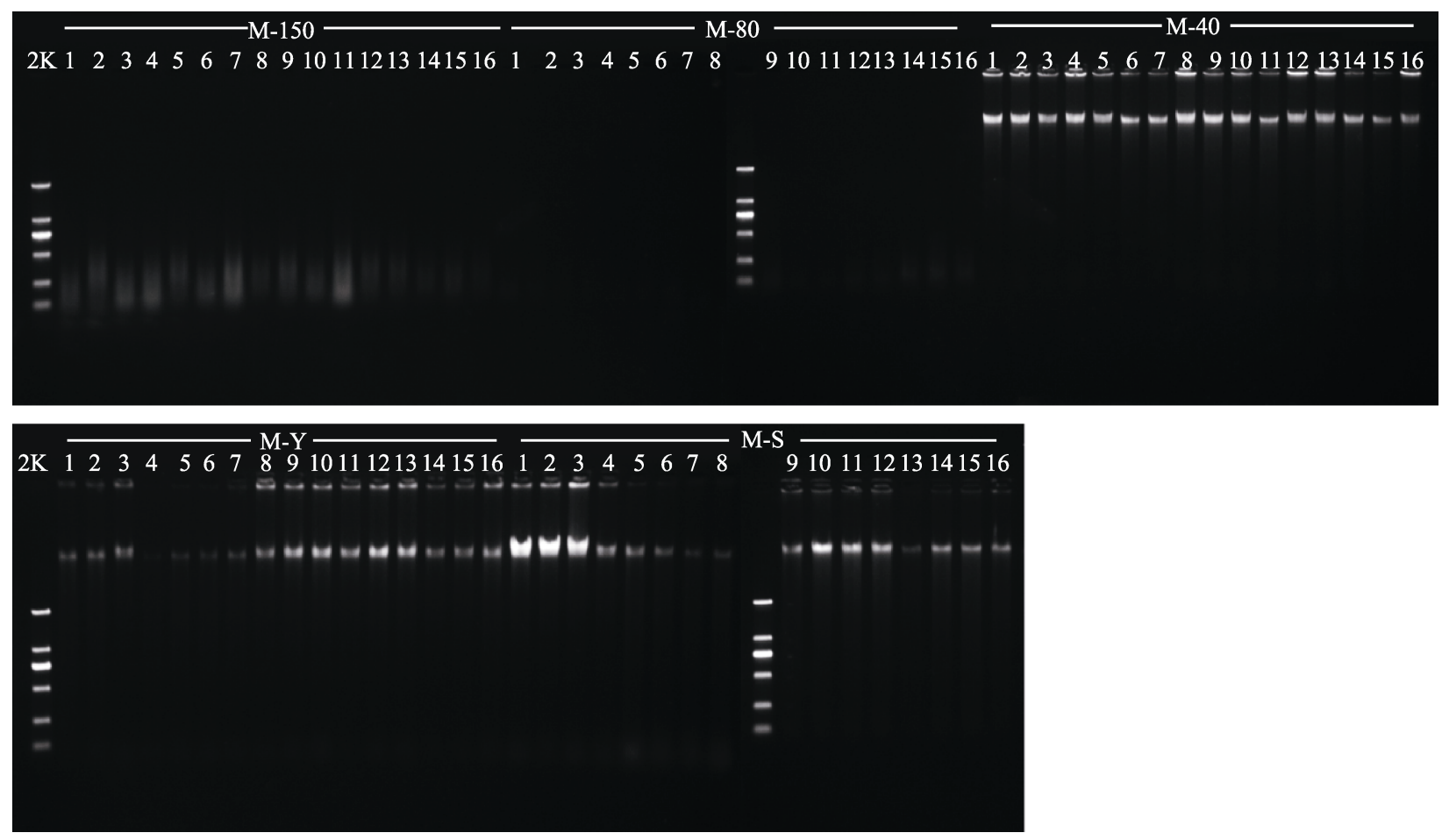

图2 5种不同干燥方式处理的山麦冬(M)总DNA电泳图。150, $150{ }^{\circ} \mathrm{C}$ 烘干处理; $80,80{ }^{\circ} \mathrm{C}$ 烘干处理; $40,40{ }^{\circ} \mathrm{C}$ 烘干处理; Y, 吸 水纸压制干燥; $\mathrm{S}$, 硅胶干燥; $2 \mathrm{~K}$, DNA ladder中最长的DNA片段为 $2000 \mathrm{bp}$ 。

Fig. 2 Genomic DNA in specimens of Liriope spicata (M) obtained with five different drying methods. 50 , drying at $150{ }^{\circ} \mathrm{C}$; 80 , drying at $80^{\circ} \mathrm{C} ; 40$, drying at $40^{\circ} \mathrm{C}$; Y, natural drying; S, silica gel drying; $2 \mathrm{~K}, 2 \mathrm{~kb}$ plus DNA ladder. 

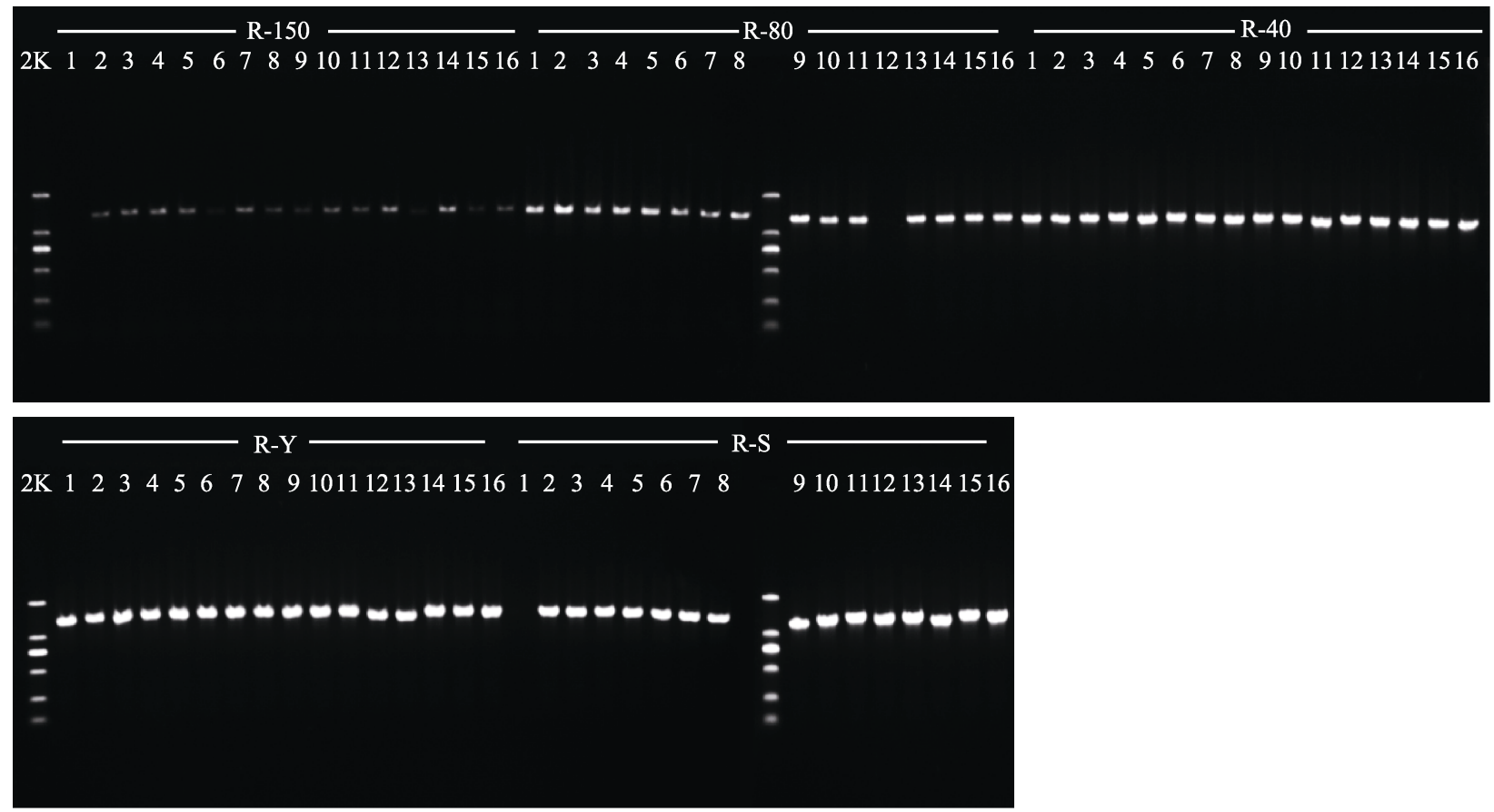

图3 日本晚樱(R)经5种不同干燥方式处理后PCR凝胶电泳检测结果。150, $150{ }^{\circ} \mathrm{C}$ 烘干处理; $80,80{ }^{\circ} \mathrm{C}$ 烘干处理; $40,40{ }^{\circ} \mathrm{C}$ 烘 干处理; Y, 吸水纸压制干燥; S, 硅胶干燥; 2K, DNA ladder中最长的DNA片段为2 $000 \mathrm{bp}$ 。

Fig. 3 Agarose gel electrophoresis of PCR products in specimens of Prunus serrulata var. lannesiana (R) obtained with five different drying methods. 150 , drying at $150{ }^{\circ} \mathrm{C} ; 80$, drying at $80{ }^{\circ} \mathrm{C} ; 40$, drying at $40{ }^{\circ} \mathrm{C}$; Y, natural drying; S, silica gel drying; $2 \mathrm{~K}$, $2 \mathrm{~kb}$ plus DNA ladder.
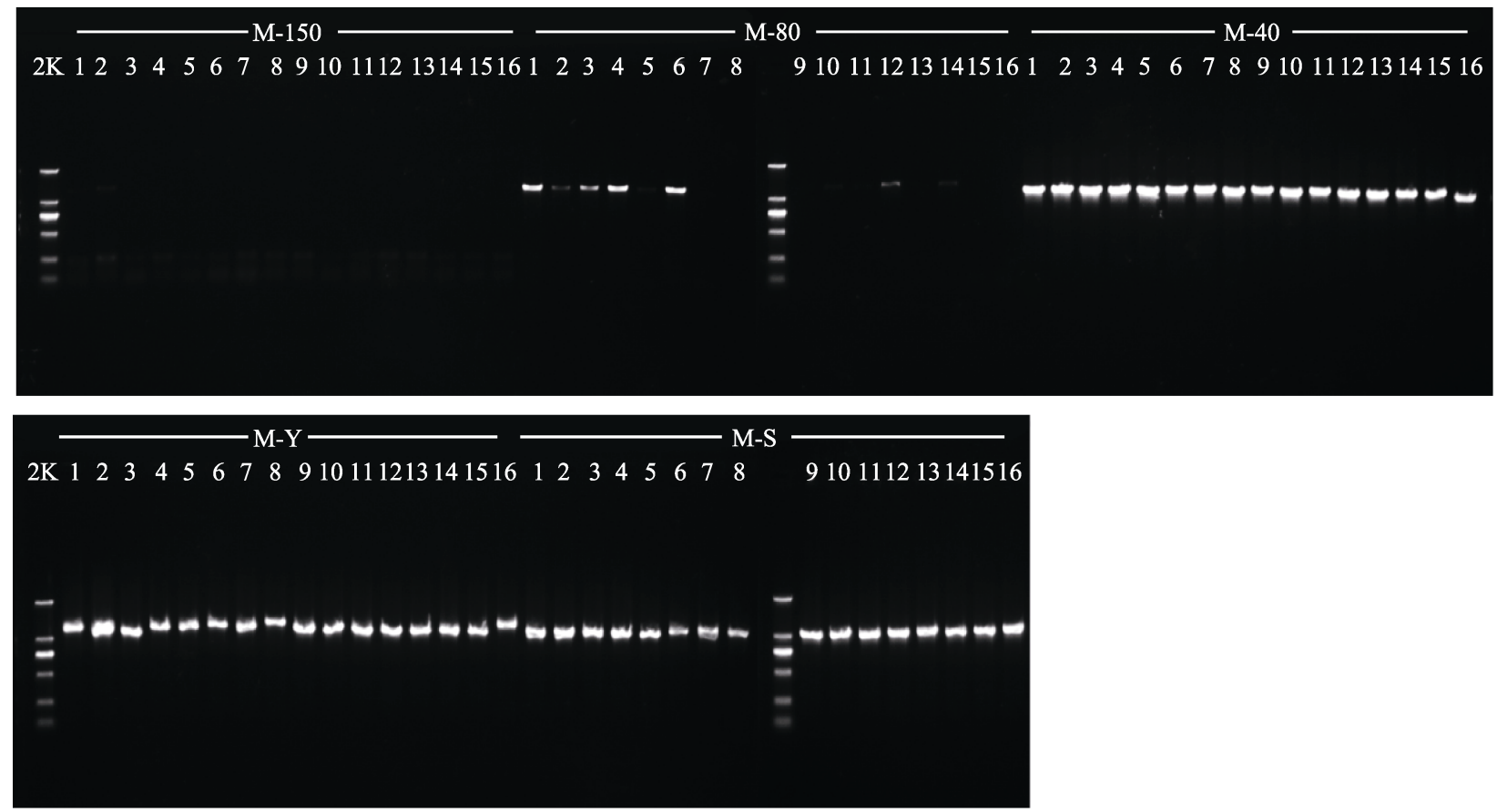

图4 山麦冬 $(\mathrm{M})$ 经5种不同干燥方式处理后PCR凝胶电泳检测结果。 $150,150{ }^{\circ} \mathrm{C}$ 烘干处理; $80,80{ }^{\circ} \mathrm{C}$ 烘干处理; $40,40{ }^{\circ} \mathrm{C}$ 烘干 处理; $\mathrm{Y}$, 吸水纸压制干燥; S, 硅胶干燥; 2K, DNA ladder中最长的DNA片段为2 $000 \mathrm{bp}$ 。

Fig. 4 Agarose gel electrophoresis of PCR products in specimens of Liriope spicata (M) obtained with five different drying methods. 150 , drying at $150{ }^{\circ} \mathrm{C} ; 80$, drying at $80^{\circ} \mathrm{C}$; 40 , drying at $40{ }^{\circ} \mathrm{C}$; Y, natural drying; $\mathrm{S}$, silica gel drying; $2 \mathrm{~K}, 2 \mathrm{~kb}$ plus DNA ladder.

产物浓度最低。日本晚樱经 $80{ }^{\circ} \mathrm{C}$ 烘干处理后PCR 产物浓度与硅胶干燥、吸水纸压制干燥浓度无显著
区别，而山麦冬经 $80{ }^{\circ} \mathrm{C}$ 烘干处理后PCR产物浓度 与硅胶干燥、吸水纸压制干燥相比浓度较低。 


\section{3 讨论}

\section{1 分子标本不同干燥方式的比较}

根据分光光度计和总DNA琼脂糖凝胶电泳图 结果分析显示, 虽然 $150{ }^{\circ} \mathrm{C}$ 烘干处理提取的DNA经 分光光度计测得的DNA浓度较高, 但电泳图中长片 段DNA含量少，降解严重; 但经 $40{ }^{\circ} \mathrm{C}$ 烘干和硅胶 干燥两种干燥方法处理的样品不仅可以通过分光光 度计检测到较高浓度的DNA, 同时可以通过琼脂糖 凝胶电泳看出长片段DNA浓度较高。根据PCR产物 浓度统计学分析显示, 5 种干燥方式中, $40{ }^{\circ} \mathrm{C}$ 烘干 处理的样品PCR产物浓度最大; 硅胶干燥和吸水纸 压制干燥法浓度稍低, $150{ }^{\circ} \mathrm{C}$ 烘干处理的样品PCR 产物浓度最低。从总 DNA浓度、品质以及PCR产物 浓度等结果可以得出, $40{ }^{\circ} \mathrm{C}$ 烘干处理效果最好, 其 次是硅胶干燥和吸水纸压制干燥法, $150{ }^{\circ} \mathrm{C}$ 烘干处 理较上述方法稍差。

总DNA电泳显示的实验结果中, 日本晚樱 $80{ }^{\circ} \mathrm{C}$ 烘干处理样品所提取的长片段DNA浓度高 于 $150{ }^{\circ} \mathrm{C}$ 烘干处理, 而山麦冬 $80{ }^{\circ} \mathrm{C}$ 烘干处理所 得长片段DNA浓度低于 $150{ }^{\circ} \mathrm{C}$ 烘干处理; 日本晚 樱 $80{ }^{\circ} \mathrm{C}$ 烘干 PCR 产物与吸水纸压制干燥法无显 著区别, 而山麦冬 $80{ }^{\circ} \mathrm{C}$ 烘干 $\mathrm{PCR}$ 产物浓度较吸水 纸压制干燥法低。日本晚樱的结果符合预期, 因 为高温容易造成DNA的降解, 所以 $150{ }^{\circ} \mathrm{C}$ 烘干处 理的DNA浓度低, 而 $80{ }^{\circ} \mathrm{C}$ 烘干处理的DNA浓度 高。而山麦冬 $80{ }^{\circ} \mathrm{C}$ 烘干处理所得DNA为什么反而 比 $150{ }^{\circ} \mathrm{C}$ 烘干处理更差呢? 这是由于 $80{ }^{\circ} \mathrm{C}$ 烘干时, 山麦冬叶片质地较厚, 且叶表皮具有发达的角质层 和丰富的蜡质(韦存虚等, 2008), 有较好的保水性, 在烘干时样品湿度一时无法降低一一高湿度样品在 较高温度下处理较长时间是导致DNA严重降解的 原因。实验中这一现象提示我们, 对于山麦冬这样叶 片含水量大、角质层较厚的植物, 应在烘干前将叶片 尽量剪碎, 使样品可以迅速干燥, 减少DNA降解。

在本次实验中, 采用吸水纸压制干燥的方式对 标本进行干燥处理后, 所提取的DNA产率较高, PCR产物浓度也较高。而在以往分子材料保存方法 的研究中, 不建议使用吸水纸压制干燥法对标本进 行干燥处理, 其原因是吸水纸压制干燥受环境影响 较大, 如果样本干燥不彻底, DNA则会在短时间内 降解。本次实验中使用吸水纸对标本进行干燥时更
换吸水纸频率高, 植物标本干燥相对迅速, 这可能 是本实验中DNA降解程度降低的主要原因。但由于 野外环境多变, 频繁更换吸水纸消耗大量人力物 力、不易实施，因此不推荐采用吸水纸压制干燥的 方式处理植物分子标本。

本实验通过 150 、 80 和 $40{ }^{\circ} \mathrm{C}$ 烘干干燥, 吸水纸 压制干燥, 硅胶干燥 5 种方法对植物新鲜叶片进行 干燥处理。选择 $150 、 80$ 和 $40{ }^{\circ} \mathrm{C} 3$ 种温度形成温度 梯度, 其中 $40{ }^{\circ} \mathrm{C}$ 模拟电热毯、吹风机及小型便携烘 箱远离通风口处的温度及电热毯温度, $80{ }^{\circ} \mathrm{C}$ 模拟小 型便携烘干机近通风口温度, $150{ }^{\circ} \mathrm{C}$ 模拟极端温度; 吸水纸压制干燥为目前使用最广泛的标本干燥方法; 硅胶干燥法是众多野外采集者进行野外采集工作时 公认的一种简单可行的分子标本干燥方法。但是在 野外采集工作中, 吸水纸压制干燥法干燥的叶片受 环境影响较大, 在湿度大的地区或在阴雨天气标本 会因空气湿度增加而吸水, 导致标本返潮, 分子标 本将可能发生降解。使用硅胶干燥可以控制植物标 本的含水量, 但有许多不便。因此, 在野外标本采集 时使用硅胶干燥法处理分子标本具有较大的局限 性。在诸多方面, $40{ }^{\circ} \mathrm{C}$ 烘干的方式优于硅胶干燥, 如在野外采集过程中 $40{ }^{\circ} \mathrm{C}$ 烘干与电热毯、吹风机和 小型便携烘箱远出风口温度相当, 而电热毯、吹风 机及小型便携烘箱均方便携带, 在不方便用电的环 境还可以利用火烘烤等方式实现烘干，这些烘干方 式都易于操作, 且不需携带大量耗材。

总体上看, 经 $40{ }^{\circ} \mathrm{C}$ 烘干处理的样品不仅总DNA 浓度及长片段DNA浓度较其他干燥方式高, 而且 $\mathrm{PCR}$ 产物的浓度高于其他干燥方式。基于以上结果, 建议在野外采集被子植物分子标本时, 使用 $40{ }^{\circ} \mathrm{C}$ 烘干干燥法对分子标本进行干燥处理，避免分子标 本快速降解，同时解决硅胶干燥法回收硅胶使用时 造成的污染问题，还可以节省携带、更换大量硅胶 材料所耗费的人力。硅胶干燥法可作为烘干干燥法 的备选方案, 适用于少量分子标本采集或不便实施 烘干干燥法时的采集。

\section{2 在实践操作中需要注意的问题}

$40{ }^{\circ} \mathrm{C}$ 烘干处理是一种简单方便的植物分子标 本干燥方式, 实验证明这种干燥方式可以更快速地 干燥分子标本, 减少DNA的降解。为保证实践操作 能够快速又安全地完成, 我们在使用这一方法时应 注意以下几点内容: 
在样品烘干处理前, 都需适当折断、剪开, 以 便于干燥迅速, 尤其是肉质植物, 更应注意这一点。 不同号标本在烘干前需置于不同的茶包袋中, 茶包袋上标注采集号, 避免样品相互污染。

使用电热毯时应注意防火, 不可将电热毯折叠 使用, 为了保持较稳定温度, 可以在电热毯的样品 上覆盖一层遮蔽物, 如耐热塑料网或报纸。电热段 用于烘干分子标本时, 不可再用于其他用途, 如不 可同时用于加热被裖、衣物, 以防分子标本返潮或 被压碎。

使用吹风机或烘干机烘干时，可以使用两头开 口的麻袋或耐热的塑料袋，一头包裹吸风机或烘干 机出风口, 一头开放形成风道, 在风道中和风道上 部放置待干燥样品。但要注意样品距离出风口的距 离, 根据经验, $40{ }^{\circ} \mathrm{C}$ 的位置位于手感稍暖处。在实 际操作中, 即使温度稍高一些, 也不会对样品造成 严重影响。使用烘干机干燥分子标本时，同样不可 同时烘干其他物品, 尤其不可同时烘干潮湿的衣 物、鞋袜, 避免干燥的分子标本再次吸水。在烘干 过程中应注意不过度加热, 分子标本完全干燥后, 应及时移出。

完全干燥的标本, 需要立即置于密封袋中密封 保存, 密封袋中保留少量干燥的变色硅胶, 作为指 示剂。野外要经常性检察变色指示硅胶, 因为密封 袋漏气等因素会造成密封袋内湿度上升, 变色硅胶 吸水变色, 这时要及时置换干燥的硅胶、更换密封 袋后密封。

基金项目 地方高校国家级大学生创新创业训练计 划(201510094011)。

致谢 感谢河北师范大学生命科学学院刘海燕老 师在数据分析上提供的帮助。感谢河北师范大学生 命科学学院李琳老师对论文修改提供的帮助。感谢 河北师范大学博士基金(L2015B13)和河北师范大学 研究生创新资助项目(xj2016034)的资助。

\section{参考文献}

Alexander PJ, Rajanikanth G, Bacon CD, Donovanbailey C (2007). Recovery of plant DNA using a reciprocating saw and silica-based columns. Molecular Ecology Notes, 7, 5-9.

Cai XZ, Liu KM, Long CL (2008). DNA extraction from dried leaves and PCR amplification of Colocasia. Chinese Wild
Plant Resources, 27(1), 51-57. (in Chinese with English abstract) [蔡秀珍, 刘克明, 龙春林 (2008). 野生芋属植 物干叶片DNA的提取及PCR扩增. 中国野生植物资源, 27(1), 51-57.]

Chase MW, Hills HH (1991). Silica gel: An ideal material for field preservation of leaf samples for DNA studies. Taxon, 40, 215-220.

Cliquet S, Jackson MA (1997). Comparison of air-drying methods for evaluating the desiccation tolerance of liquid culture-produced blastospores of Paecilomyces fumosoroseus. World Journal of Microbiology and Biotechnology, 13, 299-303.

Doyle JJ, Dickson EE (1987). Preservation of plant samples for DNA restriction endonuclease analysis. Taxon, 36, 715722.

He TM, Chen XS, Wu Y (2004). Preparation of DNA from silica gel dried leaves of Rosaceae. Journal of Shihezi University (Natural Science), 22, 316-319. (in Chinese with English abstract) [何天明, 陈学森, 吴燕 (2004). 从蓄薇科果树硅胶干燥叶片中制备DNA. 石河子大学 学报(自然科学版), 22, 316-319.]

Heenan, PB, Goeke DF, Houliston GJ, Lysak MA (2012). Phylogenetic analyses of ITS and $r b c L$ DNA sequences for sixteen genera of Australian and New Zealand Brassicaceae result in the expansion of the tribe Microlepidieae. Taxon, 61, 970-979.

Jing XM, Chu YX, Tang GG, Zhang YC, Liu Z, Zhang H (2008). Effects of different sample preserving methods on genomic DNA extraction of Chimonanthus praecox and their ISSR-PCR validation. Molecular Plant Breeding, 6, 387-392. (in Chinese with English abstract) [靖相密, 褚 云霞, 汤庚国, 张永春, 刘忠, 张慧 (2008). 不同保存 方法对蜡梅总DNA提取效果的影响及ISSR-PCR验证. 分子植物育种, 6, 387-392.]

Li JL, Wang S, Yu J, Wang L, Zhou SL (2013). A modified CTAB protocol for plant DNA extraction. Chinese Bulletin of Botany, 48, 72-78. (in Chinese with English abstract) [李金璐，王硕，于婧，王玲，周世良 (2013). 一 种改良的植物DNA提取方法. 植物学报, 48, 72-78.]

Liston A, Rieseberg LH, Adams RP, Do N, Zhu GL (1990). A method for collecting dried plant specimens for DNA and isozyme analyses, and the results of a field test in Xinjiang, China. Annals of the Missouri Botanical Garden, 77, 859-863.

Qiu NW, Liu Q, Liu H (2015). Multiple comparison data in statistical analysis. Journal of Biomathematics, 30, 535-541. (in Chinese with English abstract) [邱念伟, 刘 倩, 刘慧 (2015). 生物学实验数据统计分析中的多重比 较法. 生物数学学报, 30, 535-541.]

Särkinen T, Staats M, Richardson JE, Cowan RS, Bakker FT (2012). How to open the treasure chest? Optimising DNA 
extraction from herbarium specimens. PLOS ONE, 7, e43808. doi: 10.1371/journal.pone.0043808.

Staats M, Cuenca A, Richardson JE, Ginkel RV, Petersen G, Seberg O, Bakker FT (2011). DNA damage in plant herbarium tissue. PLOS ONE, 6, e28448. doi: 10.1371/journal. pone. 0028448 .

Taggart JB, Hynes RA, Prodöuhl PA, Ferguson A (1991). A simplified protocol for routine total DNA isolation from salmonid fishes. Journal of Fish Biology, 40, 963-965.

Wang XD, Wang ZP, Zou YP (1996). An improved procedure for the isolation of nuclear DNA from leaves of wild grapevine dried with silica gel. Plant Molecular Biology Reporter, 14, 369-373.

Wei CX, Xie PS, Zhou WD, Chen YF, Zhang J, Huai HY (2008). Observation on morphological structure of leaf epidermis of Ophiopogon japonicus, Liriope spicata and
L. platyphylla. Journal of Plant Resources and Environment, 17(4), 9-15. (in Chinese with English abstract) [韦 存虚, 谢佩松, 周卫东, 陈义芳, 张军, 淮虎银 (2008). 麦冬、土麦冬和阔叶土麦冬叶表皮形态结构的观察. 植 物资源与环境学报, 17(4), 9-15.]

Xie Z, Ge S, Hong D (1998). Preparation of DNA from silica gel dried mini-amount of leaves of Oryza rufipogon for RAPD study and total DNA bank construction. Acta Botanica Sinica, 41, 807-812.

Xu C, Dong W, Shi S, Cheng T, Li CH, Liu YL, Wu P, Wu HK, Gao P (2015). Accelerating plant DNA barcode reference library construction using herbarium specimens: Improved experimental techniques. Molecular Ecology Resources, 15, 1366-1374.

责任编委: 邓建明 责任编辑: 李 敏 